\title{
Ekmeklik Buğday Islah Programlarında Gluten Kalitesinin Değerlendirilmesi İçin GlutoPik Parametrelerinin Kullanılabilirliğinin Araştırılması
}

\author{
*Yaşar KARADUMAN Arzu AKIN Serap TÜRKÖLMEZ Zafer Şaban TUNCA \\ Geçit Kuşağı Tarımsal Araştırma Enstitüsü Müdürlüğü \\ *Sorumlu yazar e-posta (Corresponding author; e-mail): yasar.karaduman@ghtb.gov.tr
}

Geliş Tarihi (Received): 21.04.2015

Kabul Tarihi (Accepted): 15.06.2015

\section{Öz}

Gluten kalitesi buğday ununun pişme özelliklerinin değerlendirilmesinde temel kriterlerin başında gelir. Gluten kalitesinin hızlı, kolay ve tekrarlanabilir metotlarla belirlenmesi buğday ıslah programları için büyük önem arz etmektedir. GlutoPik parametreleri bu anlamda oldukça önemli bilgiler sağlamaktadır. Bu çalışmada, GlutoPik parametrelerinin ıslah programlarında materyalin kalite değerlendirilmesinde kullanılabilirliğini araştırılmıştır. Bu amaçla piyasadan temin edilen dört temel un grubuna ait unlar ve ekmeklik buğday ıslah programındaki melez bahçesi materyali GlutoPik özellikleri bakımından değerlendirilmiştir. Piyasadan temin edilen unlarının analizi sonucunda gluten maksimum direnci (BEM), gluten maksimum dirençten $15 \mathrm{~s}$ sonraki direnç (PM) ve gluten maksimum dirençten 15 s önceki direnç (BM) değerlerinin ıslah programlarında oldukça yararlı olabileceği öngörülmüştür. Bu parametrelerden melez bahçesinde özellikle BEM ve PM değerleri ebeveynler arasında ayırt edici bulunmuştur. BM değeri konusunda daha ayrıntılı çalışmalar yapılması gerekmektedir. Önümüzdeki yıllarda daha kapsamlı değerlendirme sonrası çalışmada öne çıkan ebeveynlerin farklı amaçlı un üretimi için kalitesi yüksek yeni buğday çeşitlerin geliştirilmesinde kullanılması düşünülmektedir.

Anahtar Kelimeler: Gluten, GlutoPik, buğday, kalite, un, ıslah

\section{Investigating the Availability of GlutoPeak Parameters for Evaluation of Gluten Quality in Bread Wheat Breeding Programs}

\begin{abstract}
Gluten quality is one of the basic criteria in the evaluation of baking properties of flour. Determination of gluten quality with fast, easy and reproducible methods is great importance for wheat breeding programs. GlutoPeak parameters bring significant advantages in this respect. In this study, it was investigated the availability of GlutoPeak parameters in quality evaluation of material in breeding programs. For this purpose four basic flours supplied from market and crossing nursery material in bread wheat breeding program were evaluated in terms of GlutoPeak properties. As a result the analysis of market flour gluten maximum resistance (BEM), 15s after maximum peak (PM) and 15s before maximum peak (AM) parameters were thought to be quite useful for breeding programs. From these parameters especially BEM and PM parameters were found distinguishing between parents in crossing nursery. It is necessary detailed studies about AM parameter. In coming years after a more comprehensive assessment it is thought to use the promising parents in development of new high-quality wheat varieties for production of different purpose-flour.
\end{abstract}

Keywords: Gluten, GlutoPeak, wheat, quality, flour, breeding

\section{Giriş}

B uğday unu su ile karıştığında gliadin ve glutenin proteinlerinin oluşturduğu yapıya gluten adı verilmektedir (Melnky et al. 2011; Doğan ve Uğur 2004). Gluten buğday ununun kalitesini belirleyen en önemli parametredir.
Günümüze kadar glutenin özellikleri ve gluten oluşumunu sağlayan etkileşimler konusunda (Butow et al. 2002; Kinsella and Hale 1984; Preston 1981) ve gluten kalitesinin belirlenmesinde yeni teknikler ve metotlar 
geliştirmek için pek çok çalışma yapılmıştır (Matsuo 1978; Chang and Ferrari 2000). Gluten kalitesini gösteren viskoelastik ve kohezif denge her ürün için farklıdır ve optimum düzeyde olması gerekir (Veraverbeke and Delcour 2002). Gluten proteinlerinin bu dengesi büyük oranda genetik olarak kontrol edilmektedir (Payne et al. 1982; Troccoli et al. 2000). Bu yüzden ekmeklik buğday ıslah programlarında gluten kalitesi, değerlendirilmesi gereken en önemli kriterlerden birisidir (Chandi and Seetharaman 2012).

Gluten kalitesinin değerlendirilmesinde klasik metotlarla gluten elde edilmesi zaman alıcı bir analizdir (Anonim 2015; Miralbes 2004); aynı zamanda gluten harici bileşenlerin çok iyi ayrılması gerekir. Su absorpsiyon kapasitesi, gluten indeks değeri, sedimentasyon değeri, solvent tutma kapasitesi, gliadin/glutenin oranı gibi kimyasal yolla tahmini testler ile gluten kalitesi değerlendirilmesi yaygın olarak kullanılmakla birlikte (Dick and Quick 1983; Hu and Shang 2007; Kweon et al. 2009); bu testlerde tekrarlanabilirlik düşük olabilmektedir (Chandi and Seetharaman 2012). Hamur reolojik özellikleri, elektroforetik ve immunolojik metotlar ise daha kapsamlı bilgiler sağlayan testlerdir (Lukow et al. 1989; Brett et al. 1993; Hill et al. 1999). Hamur reolojik analizleri en iyi ürün özelliklerini tahminleme yöntemleri olsalar da zaman almakta ve fazla miktarda numuneye intiyaç duyulmaktadır (Chandi and Seetharaman 2012).

Son yıllarda geliştirilen Brabender GlutoPik cihazı ile hızı bir şekilde gluten kalitesi ayırt edilebilmektedir. Bu cihazda fazla miktarda suyun olduğu un su karışımına uygulanan yüksek karıştırma kuvveti ölçülmektedir (Melnky et al. 2011). Cihazda agregasyon özelliklerinin ölçülerek gluten kalitesinin belirlenmesi için öncelikle gluten ayrılmakta; daha sonra gluten ağı oluşmakta ve devam eden hızlı karıştırma ile oluşan ağ parçalanmaktadır. Maksimum noktaya ulaşma için geçen zaman, pik yüksekliği ve takip eden pikteki düşüş gluten kalite değerlendirmesinde temel bilgilerdir ve oldukça kısa sure içerinde ölçülebilmektedir (Anonim 2015). Cihaz otomatik olarak değerlendirerek elde edilen pikte gluten ağının oluştuğu ve maksimum pikteki direnci ve maksimumun $15 \mathrm{~s}$ öncesi ve $15 \mathrm{~s}$ sonrasındaki direnci vermektedir. Ayrıca agregasyonun başladığı ve maksimum pike ulaşmak için geçen zamanda elde edilmektedir. 3-10 g örnek kullanılarak hatta tam buğday ununda dahi bu özellikler belirlenebilmekte bu da testi ıslahçı ve sektör açısından oldukça değerli kılmaktadır (Chandi and Seetharaman 2012; Anonim 2013).

Geliştirilecek yeni ekmeklik buğday çeşitlerinin gluten kalitesinin arzu edilen ürün grubu için uygun olması kalitesinin yüksekliğini göstermektedir. Islah programlarında farklı kademelerde materyal sayısı oldukça fazladır. Seleksiyonu için zaman oldukça kısadır ve bazı kademelerde numune miktarı oldukça azdır. GlutoPik cihazının ıslah programları için oldukça önemli kolaylıklar getireceği öngörülmektedir.

Bu çalışmada GlutoPik cihazının ekmeklik buğday ıslah programlarında kullanılabilirliği değerlendirilmiştir. Bunun için öncelikli olarak piyasadan temin edilen farklı amaçlar için kullanılan dört adet unların GlutoPik grafikleri ve öne çıkan parametreler ortaya konulmuştur. Bu paramerelere göre melez bahçesi GlutoPik cihazı ile değerlendirilmiştir. Çalışmada ümitvar genotipler melezleme çalışmalarında ebeveyn olarak kullanılmak üzere programda değerlendirmeye alınmıştır.

\section{Materyal ve Yöntem}

Çalışmada materyal olarak Eskişehir piyasasından alınan yufkalık, ekmeklik (uzun işlem), ekmeklik (kısa işlem) ve bisküvilik olmak üzere dört adet un ile Geçit Kuşağı Tarımsal Araştırma Enstitüsü Müdürlüğü ekmeklik buğday melez bahçesi materyalinden kuruda 185 ve suluda 131 genotip kullanılmıştır.

Melez bahçesi örnekleri öncelikle Buhler Labofix90 dokaj cihazında temizlenerek analize uygun hale getirilmiştir. 1000 tane ağırlığı analizi Özkaya ve Özkaya (2005)'e göre yapılmıştır. Örnekler Retsch ZM200 değirmeni ile 0.5 mm partikül iriliğinde kırmaya (tam tane ununa) öğütülmüştür (Anonim 2014). Tam tane unu örneklerinde protein miktarı ve PSI sertlik değeri analizi FOSS NIRS 6500 spektroskopi cihazı ile belirlenmiştir. Tam tane unu protein miktarı analizi için ICC-Standart No:105/1'e göre Kjeltec cihazı ile belirlenen toplam azotun 5.7 faktörü ile çarpılmasıyla elde edilen sonuçlara göre (Anonim 1980) ve PSI sertlik değeri Williams et al. (1986)'ya göre kalibre edilmistir. SDS (sodyum dodesil sülfat) sedimentasyon değeri analizi Pena et al. (1990)'da belirtilen metoda göre yapılmış ve $1 \mathrm{~g}$ tam tane ununda $25 \mathrm{ml}$ test tüplerinde analiz gerçekleştirilmiştir. GlutoPik özellikleri analizi Brabender GlutoPik cihazı ile belirlenmiştir (Brabender $\mathrm{GmbH}$ and 
Co KG, Duisburg, Almanya). Bu amaçla Melnyk et al. (2011) tarafından kullanılan yöntem kullanılmıştır. Analizde $8.5 \mathrm{~g}$ un ve $9.5 \mathrm{~g} \mathrm{0,5 \textrm {M }}$ $\mathrm{CaCl} 2$ kullanılarak; analiz $34 \mathrm{OC}$ sabit sıcaklık ve 900 rpm sabit karıştırma hızında 3 dakikada tamamlanmıştır. GlutoPik cihazında başlıca 5 parametre elde edilmektedir (Şekil 1).

Bunlardan LOT değeri gluten agregasyonunun (bir araya gelme) başladığı zamanı; BEM değeri gluten maksimum direncini; PMT değeri gluten maksimum dirence ulaşmak için geçen zamanı; BM değeri maksimum dirençten $15 \mathrm{~s}$ önceki direnci ve PM değeri $15 \mathrm{~s}$ sonraki direnci ifade etmektedir (Chandi and Seetharaman 2012). LOT ve PMT değerleri hamur yoğurma süresi ile ilgili özelliklerdir. BEM,PMT ve BM değerlerinin yüksekliği glüten dayanımının fazla olduğunu göstermektedir. Özellikle glüten dayanımının fazlalığı ekmek ve yufka üretiminde istenirken; bisküvilik unlarda daha zayıf glüten istenilen ürün yapısı için gereklilik olmaktadır.

Piyasadan temin edilen unlarda kalite analizleri tesadüf bloklarında 4 tekerrürlü olarak varyans analizleri ve melez bahçesi örneklerinde regresyon (R2) katsayısı hesaplamaları JMP 5.0.1 istatistik paket programında (SAS Institute 2002) yapılmıştır. Ortalamalar arası farklılık, LSD, (\% 5) çoklu karşılaştırma testine (Steel and Torrie 1980) göre belirlenmiştir.

\section{Bulgular ve Tartışma}

Çalışmada öncelikli olarak piyasadan temin edilen ve farklı amaçlar için kullanılan unların protein miktarı ve GlutoPik özellikleri belirlenmiştir (Çizelge 1). İstenilen ürün için unda aranılan özellikler üretici firmanın istediği özelliklerdir. Bu özellikler üretilen üründe istenilen özellikleri tam anlamıla karşılamaktadır. Şekil 2'de dört un grubunun GlutoPik değerleri görülmektedir.

Protein miktarı unlarda üretici firmaların öncelikli aradığı parametredir. Kompozisyonu ile birlikte protein miktarı hamur ve ürünün pişirme, tekstür ve görünüm özelliklerini belirleyen temel faktördür (Rousset et al. 1985; Borghi et al. 1995; Guttieri et al. 2001; Carson and Edwards 2009). Çalışmada ekmek elde etmek amacıyla uzun proses kullanılan ve yüksek düzeyde ekşi maya ilave edilen unların kısa prosesle işlenen unlara göre protein miktarı daha yüksektir. Yufkalık unlarında protein miktarı yüksektir. Bisküvilik unların ise beklendiği gibi protein miktarı daha düşüktür. Protein miktarı yanında gluten kalite özelliklerinin belirlenmesi kalite değerlendirmesinde büyük önem arz etmektedir (Jirsa and Hruskova 2005).

Agregasyonun başlangıcı ile ilgili elde edilen GlutoPik grafiklerinde belli bir süre görünürken cihazın programından alınan sonuçlarda ekmeklik-kısa proses unlardan $0 \mathrm{~s}$ değeri elde edilmesi LOT değerinin program tarafından

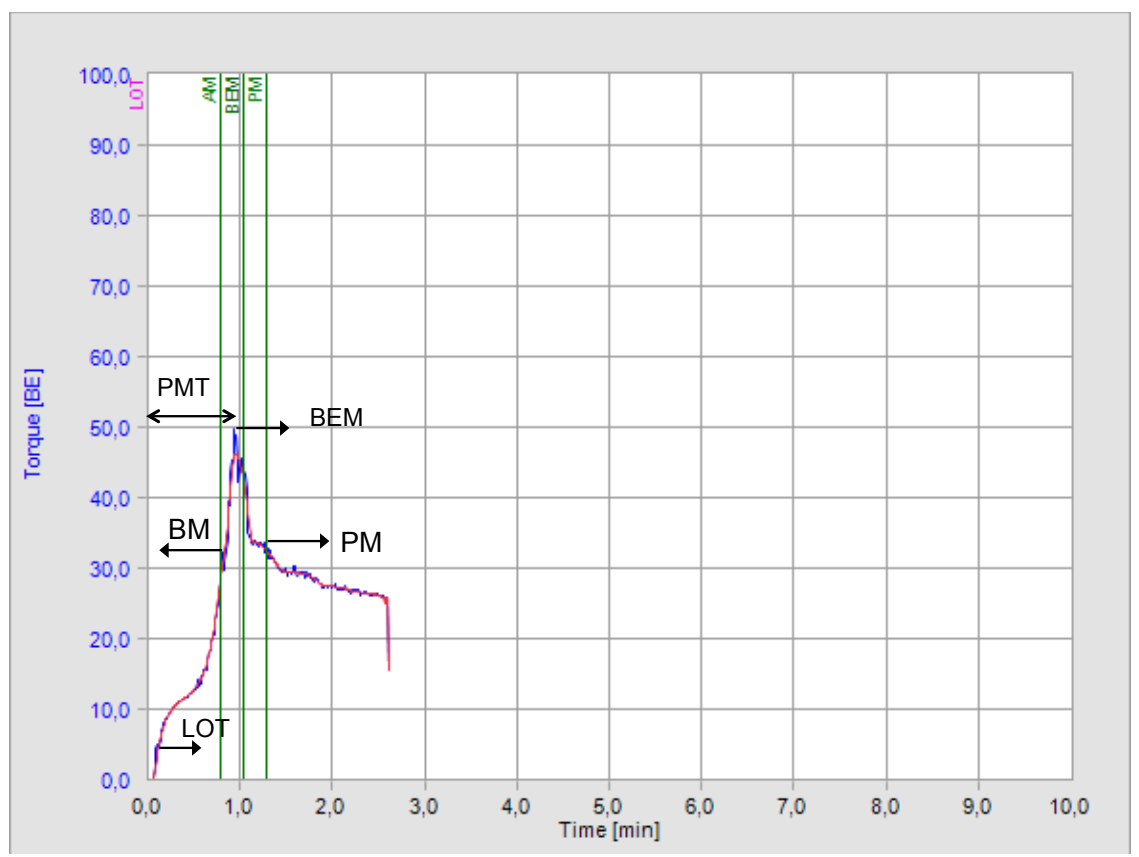

Şekil 1. GlutoPik grafiği ve değerlendirilen parametreler

Figure 1. GlutoPeak graph and evaluated parameters 
belirlenmesinde bazı sıkıntıların olduğunu göstermiştir. LOT değerleri için değişkenlik katsayısı (D.K.) da oldukça yüksektir. Optimum gluten viskoelastik özelliklerinin elde edilmesi için daha uzun sure yoğrulma uygulanan ekmeklik-uzun proses örneğinde LOT ve PMT değerleri yüksek bulunmuştur. Daha kısa yoğurma işlemi uygulanan ekmeklik-kısa sure unların daha düşük LOT ve PMT değerleri vardır. Yufkalık unun ise PMT değeri ortaderecede yüksek olmuştur. Bisküvilik ve ekmeklik-kısa proses unlarının LOT ve PMT değerleri birbirine yakın çıkmıştır. Zayıf direnci olan bisküvilik unların bu iki değerinin ekmeklik un-kısa süreye yakın olması beklenen farklılığı göstermemiştir (Şekil 2). Bunun nedenleri konusunda hamur reolojik özelliklerinde değerlendirildiği daha kapsamlı araştırma yapmak gerekmektedir.

Şekil 2'de görüldüğü gibi yufkalık unların BEM değeri oldukça yüksektir (51.3 BE). Üretilen yufkaların bir sandviç gibi içindeki gıdayı tutabilecek şekilde kolay kıvrılabilmesine izin veren esneklikte olması ve dayanıklılık yufkalık unların en önemli kalite kriteri olarak belirtilmektedir (Olçay 2000). Bu özelliklerde yırtılmadan mümkün olduğunca ince yufka hamuru elde edilmesi ancak yüksek bir direnç ile mümkün olabilmektedir. Ekmeklik-uzun proses unlarında BEM değeri yüksek olup uzun yoğurma süresi ve diğer üretim aşamaları için bu bir gereklilik olmaktadır. BEM değerinin yüksekliğinin uzun ekmek üretim prosesi için kısa prosese göre daha önemli olduğu görülmüştür.

BM değeri örneklerde oldukça farklıdır. Gluten agregasyonunun tamamlanmasından 15 s önceki direnci ifade eden BM değeri daha agregasyonun başlangıcında bile yufkalık unda yüksek bulunmuştur (41.0 BE). Bu da gluten kalitelerinin yüksekliğini göstermektedir. Bisküvilik unların ise 11.8 BE gibi düşük $\mathrm{BM}$ değeri vardır. Düşük BM değeri bisküvilik un hamurlarında istenilen zayıf gluten yapısının göstergesidir. Yufkalık kadar olmasa da ekmeklik-un uzun proses için istenilen glutenin başlangıç direnci kısa prosese göre biraz daha fazladır (Şekil 2).

Çizelge 1. Türkiye'de üzümün potansiyel yetişme alanları haritası için kullanılan parametreler ve sınır değerleri

Table 1. Parameters and their threshold values for determining potential grape cultivation areas of Turkey

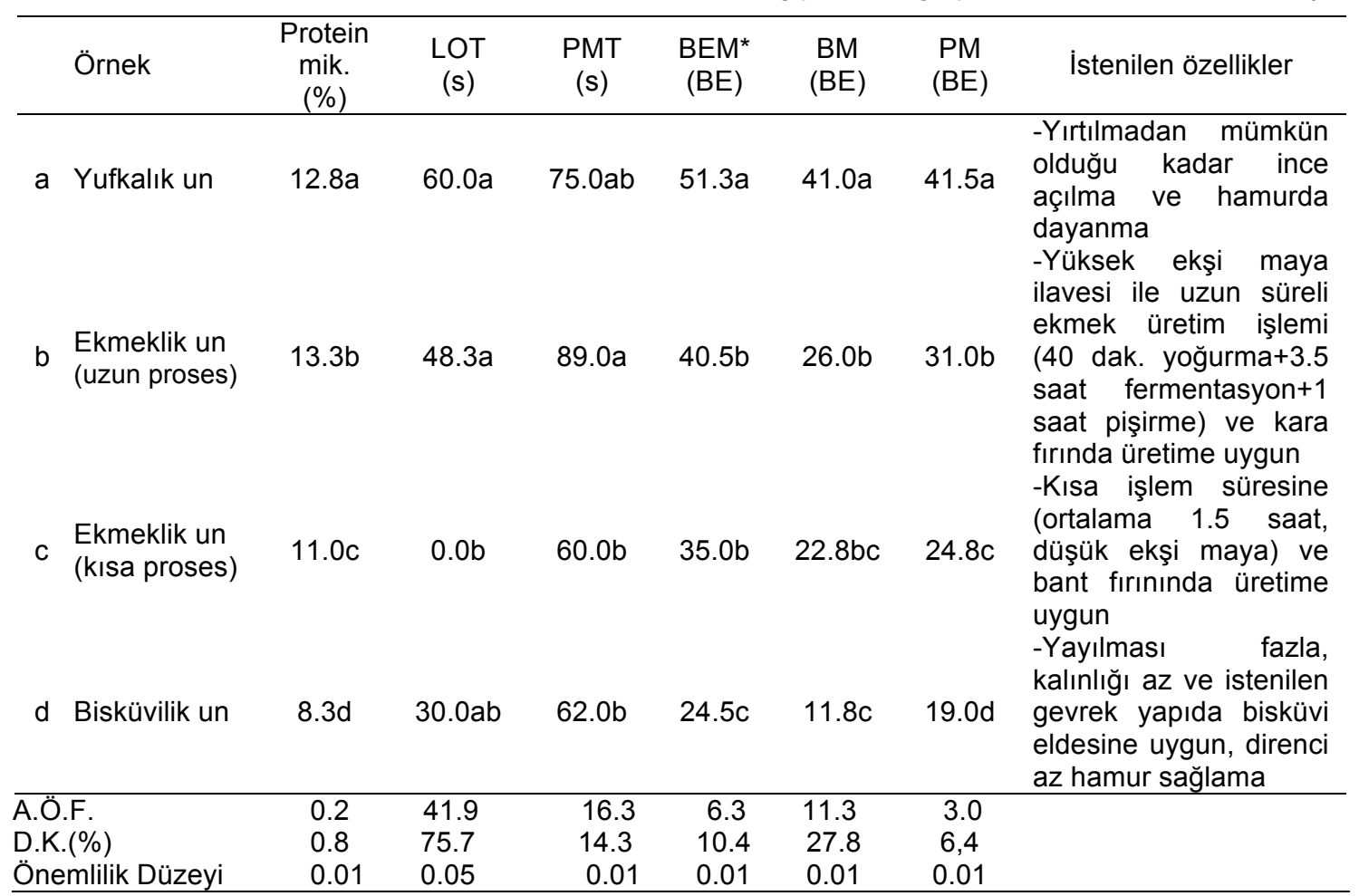

*BEM:gluten maksimum direnci, BM:gluten maksimum dirençten 15 s önceki direnç, PM:gluten maksimum dirençten 15 s sonraki direnç, LOT:gluten agregasyonunun başladığı zaman, PMT:gluten maksimum direncine ulaşmak için geçen zaman

${ }^{*}$ BEM:gluten maximum resistance, AM:15s before maximum peak, PM:15s after maximum peak, LOT:lift off time, PMT:peak maximum time 
Glutenin devam eden karıştırma ile birlikte zayıflamasını gösteren PM değerine bakıldığında yufkalık unların direncini daha fazla koruduğu görülmektedir (Şekil 2). Hamur açma esnasında kademeli incelmede dayanıklılık açısından bu durum oldukça önemli görülmüştür. Ekmeklik unlarda da uzun proses için gerekli unların PM değeri yüksek kalmıştır. Bisküvilik unların oldukça düşük PM değeri istenilen direnci az hamur ve dolayısıyla yayılması fazla bisküvi için gerekliliktir.

Unlardaki bir diğer farklılık grafikteki çizgisinin kalınlığında olduğu yufkalık ve uzun proses gerektiren ekmeklik unların bant kalınlığının ve titreşim aralığının fazla olduğu dikkati çekmiştir. Bisküvilik un ise ince, titreşimsiz bir bant oluşturmuştur (Şekil 2). GlutoPik ile yapılan çalışmalarda kuvvetli unların oldukça hızlı ve yüksek pikler verirken; zayıf unlarda daha uzun sürede daha düşük dirençte grafiklerin elde edildiği belirtilmektedir (Anonim 2015).

Piyasadan temin edilen bu dört un grubu ile yapılan çalışma sonucunda BEM, PM ve BM değerlerinin ıslah programlarında oldukça yararlı olabileceği düşünülmektedir. PMT değerleri belli bir farklılık gösterse de LOT değeri ile birlikte daha ayrıntılı değerlendirilmesi uygun olacaktır.
Çalışmanın 2. aşamasında ekmeklik buğday melez bahçesi GlutoPik değerleri ile birlikte değerlendirilmiştir. Melez bahçesi örneklerinde BEM, PM ve BM değerleri ile bazı kalite değerleri arasındaki regresyon (R2) değerleri Çizelge 2'de verilmiştir. Çalışmada SDS sedimentasyon değeri ve protein miktarı ile GlutoPik parametreleri arasındaki regresyon değerleri önemlidir. Özellikle SMB'de BEM ve PM değerleri ile SDS sedimentasyon değerleri arasındaki yüksek regresyon katsayıları dikkati çekmiştir. Şekil 3'de kuruda melez bahçesinde (KMB) C-SDS değeri ile BEM değeri arasındaki ilişki ve Şekil 4'de suluda melez bahçesinde (SMB) C-SDS değeri ile PM değeri arasındaki ilişki görülmektedir.

Gluten (özellikle glutenin proteinlerinin) kuvvetinin belirlenmesinde sedimentasyon testleri (SDS ve Zeleny) birçok araştırma kuruluşu tarafından kullanılmaktadır ve daha çok kalıtımın etkisi altında olan kriterlerdir (Zeleny 1971; Axford et al.1979; Koçak ve ark. 1992). Illeride yapılacak çalışmalarda bu testlere ilave olarak uzun zamandır kullanılan reolojik test parametreleri ile GlutoPik parametreleri arasındaki ilişkilerinde daha kapsamlı araştırılması uygun olacaktır.

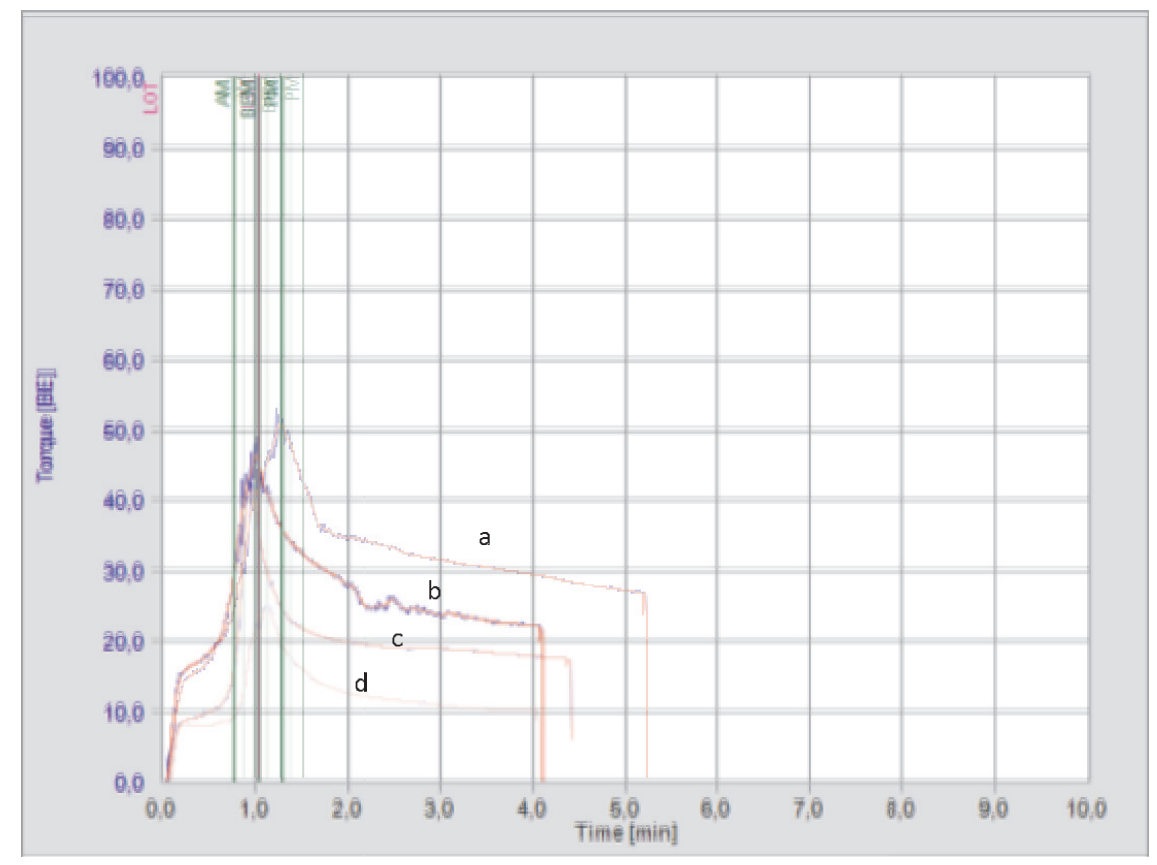

Şekil 2. Piyasadan temin edilen unların glutopik grafikleri. a:yufkalık un, b:ekmeklikun-uzun proses, c: ekmeklik un-kısa proses, d:bisküvilik un

Figure 2. Graphs of flour supplied from market. a:yufka flour, b:bread flour-long process, c:bread flour-short process, d:biscuit flour 
Karaduman ve ark. "Ekmeklik Buğday Islah Programlarında Gluten Kalitesinin Değerlendirilmesi için GlutoPik Parametrelerinin Kullanılabilirliğinin Araştırılması"

Çizelge 2. KMB ve SMB'de bazı kalite özellikleri ile GlutoPik parametreleri arasındaki regresyon katsayıları Table 2. Regression coefficients between some quality properties and GlutoPeak parameters

\begin{tabular}{lcccccc}
\hline & $\begin{array}{c}\mathrm{BEM}^{*} \\
\mathrm{kmb}, \mathrm{n}=185\end{array}$ & $\begin{array}{c}\mathrm{BEM} \\
\mathrm{smb}, \mathrm{n}=131\end{array}$ & $\begin{array}{c}\mathrm{BM} \\
\mathrm{kmb}, \mathrm{n}=185\end{array}$ & $\begin{array}{c}\mathrm{BM} \\
\mathrm{smb}, \mathrm{n}=131\end{array}$ & $\begin{array}{c}\mathrm{PM} \\
\mathrm{kmb}, \mathrm{n}=185\end{array}$ & $\begin{array}{c}\mathrm{PM}, \mathrm{smb} \\
\mathrm{n}=131\end{array}$ \\
\hline BDA & $0.05^{* *}$ & $0.07^{* *}$ & Ö.D. & Ö.D. & Ö.D. & $0.05^{* *}$ \\
C-SDS & $0.10^{* *}$ & $0.38^{* *}$ & $0.07^{* *}$ & $0.17^{* *}$ & $0.11^{* *}$ & $0.47^{* *}$ \\
PROT & $0.06^{* *}$ & $0.09^{* *}$ & $0.06^{* *}$ & $0.10^{* *}$ & $0.08^{* *}$ & $0.22^{* *}$ \\
PSI & $0.03^{*}$ & Ö.D. & $0.05^{* *}$ & $0.03^{*}$ & $0.08^{* *}$ & $0.03^{*}$ \\
\hline
\end{tabular}

**:\%1 düzeyinde önemli *:\%5 düzeyinde önemli Ö.D. :önemli değil

*BDA:1000 tane ağırığı,PSI:partikül irilik indeksi sertlik değeri, C-SDS:CIMMYT sodyum dodesil sülfat sedimentasyon değeri, PROT:protein miktarı, BEM:gluten maksimum direnci, BM:gluten maksimum dirençten $15 \mathrm{~s}$ önceki direnç, PM:gluten maksimum dirençten $15 \mathrm{~s}$ sonraki direnç, KMB:kuruda melez bahçesi, SMB:suluda melez bahçesi

*BDA:1000 kernel weight, PSI:particle size index hardness value, C-SDS:CIMMYT sodium dodesil sulphate sedimentation value, Prot:protein content, BEM:gluten maximum resistance, BM:15s before maximum peak, PM:15s after maximum peak, KMB:crossing nursery in rainfed condition, SMB:crossing nursery in irrigated condition

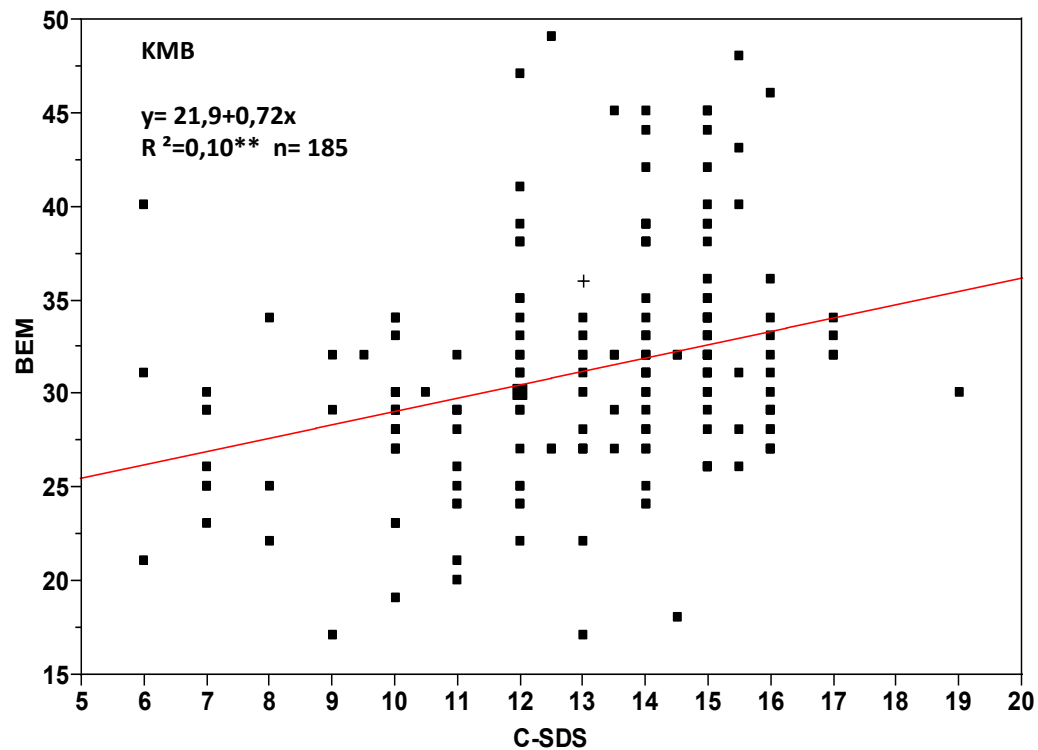

Şekil 3. Kuruda melez bahçesinde (KMB) C-SDS değeri ile BEM değeri arasındaki ilişki

Figure 3. Relationship between C-SDS and BEM in crossing nursery in rainfed condition (CNR)

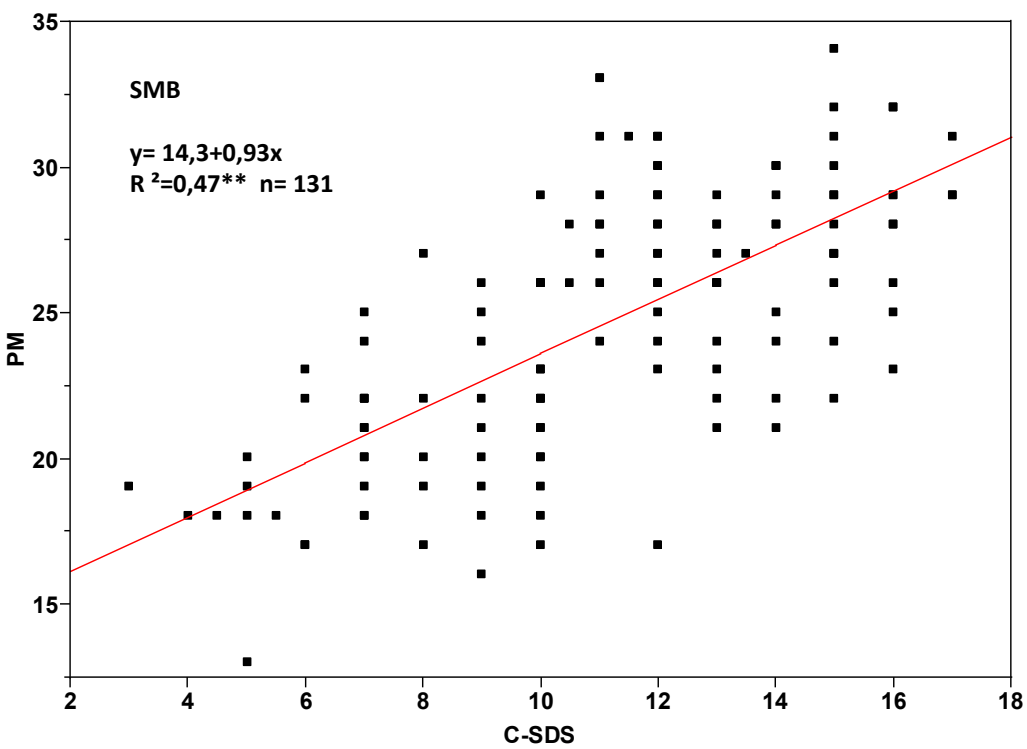

Şekil 4. Suluda melez bahçesinde (SMB) C-SDS değeri ile PM değeri arasındaki ilişki

Figure 4. Relationship between C-SDS and PM in crossing nursery in irrigated condition (CNI) 
Çalışmada LOT ve PMT değerleri melez bahçesinde ayırt edici olamazken diğer taraftan direnç değeri düşük genotiplerin bile yüksek BM değeri vermesi bu parametre konusunda daha ayrıntılı çalışmalar yapılması gerektiğini ortaya koymuştur. Çalışmada BEM ve PM değerleri ayırt edici bir özellik göstermiştir. Melez bahçesinde BEM ve PM değeri bakımından öne çıkan ebeveynler ıslah programında değerlendirileceklerdir (Çizelge 3 ve Çizelge 4). Genel olarak BEM ve PM değeri yüksek ve düşük genotiplere ait grafikler aynı grafikte bir araya getirildiğinde farklılıklar Şekil 5'de görülmektedir. Düşük BEM ve PM değerine sahip genotiplerin daha dik ve hızlı bir şekilde BEM değerlerine ulaşmaları da dikkati çekmiştir.

Çizelge 3. Melez bahçesinde BEM ve PM değeri yüksek genotipler

Table 3. Genotypes having high BEM and PM in crossing nursey

\begin{tabular}{lccccccccc}
\hline \multicolumn{1}{c}{ SIRA NO } & BDA* $^{*}$ & C-SDS & PROT & PSI & LOT & PMT & BEM & BM & PM \\
\hline SOYER02 & 37.5 & 12.5 & 14.1 & 70.4 & 60.0 & 61.0 & 49.0 & 23.0 & 34.0 \\
ALTAY2000 & 40.0 & 12.0 & 13.5 & 76.6 & 0.0 & 60.0 & 47.0 & 28.0 & 36.0 \\
FATIMA & 40.0 & 15.0 & 13.6 & 66.8 & 0.0 & 60.0 & 42.0 & 46.0 & 38.0 \\
$\begin{array}{l}\text { ORKINOS-2 } \\
\text { (BUC/5/NAPHAL/CI13449/4/ }\end{array}$ & 40.0 & 16.0 & 12.0 & 50.1 & 0.0 & 60.0 & 46.0 & 23.0 & 36.0 \\
$\begin{array}{l}\text { SEL14.53/3/LANCER//ATL6 } \\
\text { 6/CMN) }\end{array}$ & & & & & & & & & \\
SUT/*AG/MAX//CIMMYT & 38.0 & 15.0 & 11.9 & 58.6 & 0.0 & 60.0 & 44.0 & 33.0 & 33.0 \\
LINE/3/ABILENE & 38.5 & 15.5 & 10.7 & 49.9 & 600 & 61.0 & 48.0 & 19.0 & 34.0 \\
VEE 'S'/BOW 'S'/CROW 'S' & 31.0 & 14.0 & 13.6 & 51.4 & 60.0 & 65.0 & 44.0 & 19.0 & 31.0 \\
ND8212/ABILENE & 34.0 & 15.0 & 10.0 & 49.5 & 60.0 & 74.0 & 45.0 & 19.0 & 34.0 \\
MZL/IT & 47.0 & 16.0 & 12.3 & 64.6 & 60.0 & 60.0 & 44.0 & 28.0 & 32.0 \\
ALDANE & & & & & & & & & \\
\hline
\end{tabular}

*BDA:1000 tane ağılığı; C-SDS:CIMMYT sodyum dodesil sülfat sedimentasyon değeri, PROT:protein miktarı, PSI: partikül irilik indeksi sertlik değeri, BEM:gluten maksimum direnci, BM:gluten maksimum dirençten $15 \mathrm{~s}$ önceki direnç, PM:gluten maksimum dirençten $15 \mathrm{~s}$ sonraki direnç, LOT gluten agregasyonunun başladığı zaman, PMT gluten maksimum direncine ulaşmak için geçen zaman

*BDA:1000 kernel weight, C-SDS:CIMMYT sodium dodesil sulphate sedimentation value; PROT:protein content, PSI: particle size index hardness value, BEM:gluten maximum resistance, BM:15s before maximum peak,PM:15s after maximum peak, LOT:lift off time, PMT:peak maximum time

Çizelge 4. Melez bahçesinde BEM ve PM değeri düşük genotipler Table 4. Genotypes having low BEM and PM in crossing nursey

\begin{tabular}{|c|c|c|c|c|c|c|c|c|c|}
\hline SIRA NO & $\mathrm{BDA}^{*}$ & SDS & PRT & PSI & LOT & PMT & BEM & BM & PM \\
\hline \multirow{3}{*}{$\begin{array}{l}\text { ZCL/3/PGFN//CNO67/SN6 } \\
\text { 4/4/SERI/5/UA.2837/6/ATT } \\
\text { ILA/3*BCN } \\
\text { LOV26//LFN/SDY(ES84- } \\
\text { 24)/3/OPATA/3/AU/CO652 } \\
337 / / 2^{*} \text { CA8055 }\end{array}$} & & & & & & & & & \\
\hline & 44.5 & 8.0 & 10.4 & 68.7 & 0.0 & 60.0 & 25.0 & 18.0 & 19.0 \\
\hline & 40.0 & 7.0 & 10.3 & 78.5 & 0.0 & 63.0 & 25.0 & 27.0 & 33.0 \\
\hline \multirow{2}{*}{$\begin{array}{l}\text { BJN837/GRK } \\
\text { NOR/6720//YMH/3/ZZ/4/PJ } \\
\text { /HN4//GLL }\end{array}$} & 38.0 & 9.0 & 11.4 & 79.6 & 0.0 & 66.0 & 17.0 & 21.0 & 16.0 \\
\hline & 38.5 & 5.0 & 9.2 & 71.3 & 0.0 & 60.0 & 14.0 & 20.0 & 13.0 \\
\hline \multirow{2}{*}{$\begin{array}{l}\text { BEZ/3/BEZ//CNO"S"/GLL } \\
\text { CROC1/AE.SOUARROSA( } \\
\text { 205)//KAUZ }\end{array}$} & 42.5 & 6.0 & 10.6 & 72.9 & 0.0 & 60.0 & 14.0 & 20.0 & 17.0 \\
\hline & 39.0 & 7.0 & 10.6 & 76.6 & 0.0 & 60.0 & 21.0 & 28.0 & 18.0 \\
\hline \multirow{2}{*}{$\begin{array}{l}\text { NS5558/VEE"S" } \\
\text { MRS/CI14482//YMH/HYS/ } \\
\text { 3/H84160/4/RMN }\end{array}$} & 42.0 & 7.0 & 10.4 & 71.7 & 0.0 & 60.0 & 23.0 & 30.0 & 20.0 \\
\hline & 42.0 & 6.0 & 12.7 & 71.1 & 0.0 & 60.0 & 24.0 & 27.0 & 22.0 \\
\hline CRAKLIN & 40.0 & 6.0 & 8.6 & 76.4 & 0.0 & 60.0 & 24.0 & 14.0 & 17.0 \\
\hline
\end{tabular}

*BDA:1000 tane ağırlığı; C-SDS:CIMMYT sodyum dodesil sülfat sedimentasyon değeri, PROT:protein miktarı, PSI: partikül irilik indeksi sertlik değeri, BEM:gluten maksimum direnci, BM:gluten maksimum dirençten $15 \mathrm{~s}$ önceki direnç, PM:gluten maksimum dirençten $15 \mathrm{~s}$ sonraki direnç, LOT gluten agregasyonunun başladığı zaman, PMT gluten maksimum direncine ulaşmak için geçen zaman

*BDA:1000 kernel weight, C-SDS:CIMMYT sodium dodesil sulphate sedimentation value; PROT:protein content, PSI: particle size index hardness value, BEM:gluten maximum resistance, BM:15s before maximum peak,PM:15s after maximum peak, LOT:lift off time, PMT:peak maximum time 


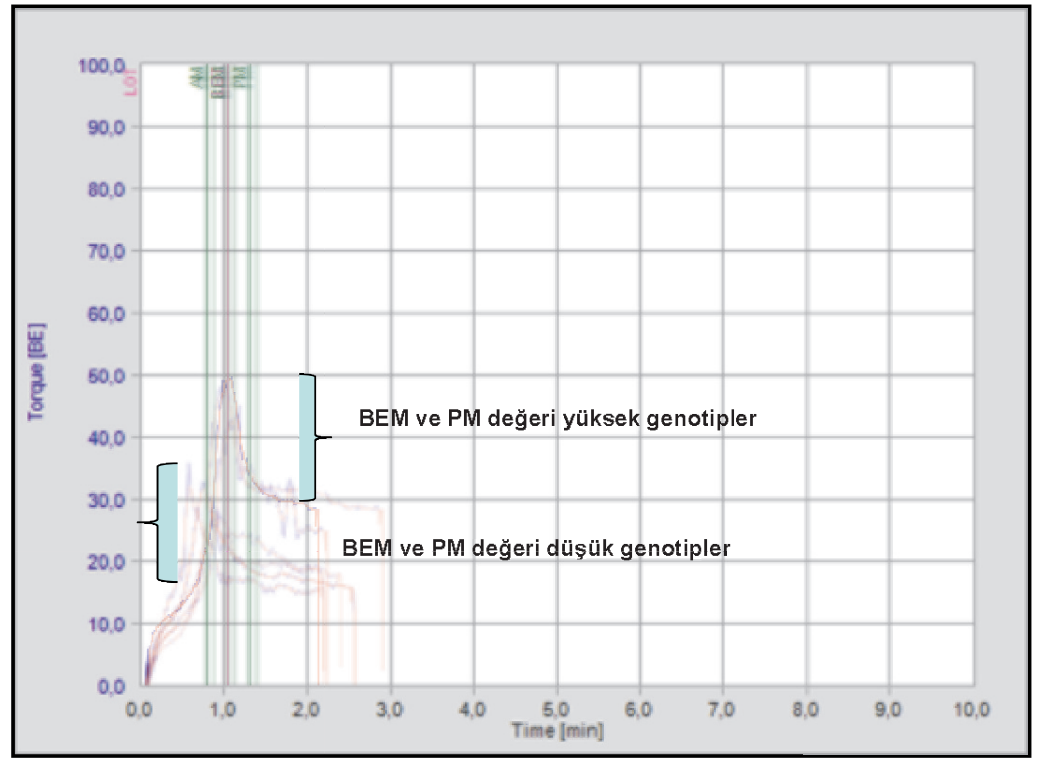

Şekil 5. BEM ve PM değerleri yüksek ve düşük genotipler

Figure 5. Genotypes having high and low BEM and PM values

\section{Sonuç}

Piyasadan temin edilebilen unlarda yapılan analizler sonucunda özellikle BEM, PM ve BM değerleri ıslah programlarına faydalı olacaktır. $\mathrm{Bu}$ parametrelerden BEM ve PM değerleri genotiplerin gluten kalitesinin belirlenmesinde ayırt edici olurken; LOT ve PMT değerleri konusunda bu farklılık görülmemiştir. BM değeri konusunda daha ayrıntılı çalışmalar yapılması gerekmektedir. Melez bahçesinde öne çıkan ebeveynlerin önümüzdeki yıllarda hamur reolojik özelliklerinin de dahil olduğu kapsamlı değerlendirmeleri sonucunda yufkalık, ekmeklik ve bisküvilik kalitesi yüksek yeni genotiplerin geliştirilmesinde ebeveyn olarak farklı kombinasyonlarda kullanılması düşünülmektedir.

İleride yapılacak çalışmalarda, araştırmada kullanılan testlere ilave olarak uzun zamandır kullanılan reolojik test parametreleri ile GlutoPik parametreleri arasındaki ilişkilerinde araştırılması uygun olacaktır.

\section{Kaynaklar}

Anonim, 1980. ICC Standard No: 105/1. Method for the determinations of crude protein in cereals and cereal products for food and for feed. Standard Methods of the International Association for Cereal Chemistry (ICC). Verlag Moritz Schafer, Detmold.

Anonim, 2013. Branender Glutopeak test cihazı. www. anamed.com.tr. (Erişim tarihi: 28.11.2013).
Anonim, 2014. http://www.retsch.com.tr/tr/ products/milling/rotor-mills/zm-200 (Erişim tarihi: 08.06.2014).

Anonim, 2015. www. Brabender.com. http://www.brabender.com/english/food/news/n ews/datensaetze/brabenderr-glutopeak-quickpeak-values-for-gluten-testing.html. (Erişim tarihi 17.03.2015)

Axford D.W.E, McDermott E.E., Redman D.G., 1979. Note on the sodium dodecyl sulphate test of bread-making quality:comparision with Pelsenke. Cereal Chemistry,56;582-584.

Brett G.M., Mills E.N.C., Tatham A.S., Fido R.J., Shewry P.R. and Morgan M.R.A., 1993. Immunochemical identification of LMW subunits of glutenin associated with breadmaking quality of wheat flour. Theoretical and Applied Genetics, 86, 442-448.

Borghi B., Giordani G., Corbellini M. 1995. Influence of crop rotation, manure and fertilizers on bread making quality of wheat (Triticum aestivum L.). European Journal of Agronomy, 4:37.

Butow B. J., Gras P. W., Haraszi R. and Bekes F. ,2002. Effects of different salts on mixing and extension parameters on a diverse group of wheat cultivars using 2-g mixograph and extensigraph methods. Cereal Chemistry, 79(6), 826-833.

Carson G.R. and Edwards N.M., 2009. Criteria of wheat and flour quality. In: Khan, K. and P.R. Shewry. (eds.). Wheat chemistry and technology 4th ed., AACC International Inc., MN, USA, pp. 97-118. 
Chandi G.K. and Seetharaman K., 2012. Optimization of gluten peak tester: A statistical approach. Journal of Food Quality, 35 (2012) 69-75.

Chang Y. K. and Ferrari M.C., 2000. A new apparatus for the evaluation of rheological properties of wheat gluten. Acta Alimentaria 29, 169-179.

Dick J.W. and Quick J.S., 1983. A modified screening test for rapid estimation of gluten strength in early-generation durum wheat breeding lines. Cereal Chemistry, 60, 319-324.

Doğan İ.S. ve Uğur T., 2004. Van ve Çevresinde yetiştirilen bazı buğdayların bisküvilik kalitesi üzerine bir araştırma. Yüzüncü Yıl Üniversitesi, Ziraat Fakültesi, Tarım Bilimleri Dergisi (Journal of Agricultural Science), 15: 139-148.

Guttieri M.J., D. Bowen D. Gannon K. O’Brien and Souza E., 2001. Solvent retention capacities of irrigated soft white spring wheat flours. Crop Science, 41:1054-1061.

Hill A.S., Geirsch T.M., Loh C.S. and Skerritt J.H., 1999. Immunoassay for wheat processing quality: Utilization of a sandwich assay incorporating and immunobilized single-chain fragment. Journal of Agricultural and Food Chemistry, 47, 4484-4490.

Hu X.Z. and Shang Y.N., 2007. A new testing method for vital gluten swelling index. Jornal of Science and Food Agriculture 87, 1778-1782.

Jirsa O, Hruskova M. and Švec I., 2007. B read features evaluation by NIR analysis. Czech Journal of Food Sciences, 25: 243-248.

Jirsa O, Hruskova M and Švec I., 2008. Near-infrared prediction of milling and baking parameters of wheat varieties. Journal of Food Engineering, $87: 21-25$

Kinsella J. E., and Hale M. L., 1984. Hydrophobic associations and gluten consistency-effects of specific anions. Journal of Agricultural and Food Chemistry, 32(5), 1054-1056.

Koçak N., Atlı A., Karababa E., Tuncer T., 1992. Macar-Yugoslav (MAYEB) ekmeklik buğday çeşitlerinin kalite özellikleri üzerine araştırmalar. Tarla Bitkileri Merkez Araştırma Enstitüsü Dergisi, 1:1, Ankara.

Kweon M., Martin R. and Souza E., 2009. Effect of tempering condition in milling performance and flour functionality. Cereal Chemistry, 86: 12-17.

Lukow O.M., Payne P.I. and Tkauchuk R., 1989. The HMW glutenin subunits composition of Canadian wheat cultivars and their association with bread-making quality. Journal of the Science of Food and Agriculture,46: $451-460$.
Matsuo R.R., 1978. Note on a method for testing gluten strength. Cereal Chemistry, 55, 259262.

Melnyk J.P., Dreisoerner J., Bonomi F., Marcone M.F. and Seetharaman K., 2011. Effect of the Hofmeister series on gluten aggregation measured using a high shear-based technique. Food Research International, 44, 893-896.

Miralbes C.,2004. Quality control in the milling industry using near infrared transmittance spectroscopy. Food Chemistry, 88: 621-628.

Olçay M., 2000. Çeşit ve Öğütme Teknolojisinin Yufkalık Un Kalitesine Etkisi. Ege Üniv. Fen Bilimleri Enst. Doktora Tezi,109 sayfa, İzmir.

Özkaya H., Özkaya B. 2005. Tahıl ve Ürünleri Analiz Yöntemleri. A.Ü. Mühendislik Fak. Gıda Müh. Bölümü Gıda Teknolojisi Yayınları N0:30, Ankara.

Payne P.I., Holt L.M., Lawrence, G.J., and Law, C.N., 1982. The genetic of gliadin and glutenin The major storage proteins of the wheat endosperm. Plant Foods for Human Nutrition, 31, 229-241.

Pena R.J., A. Amaya, S. Rajaram ve A. Mujeeb-Kazi, 1990. Variation in quality characteristics associated with some spring $1 \mathrm{~B} / 1 \mathrm{R}$ translocation wheats. Journal of Cereal Science 12, 105-112.

Preston K. R.,1981. Effects of neutral salts upon wheat gluten protein-properties.1. Relationship between the hydrophobic properties of gluten proteins and their extractability and turbidity in neutral salts. Cereal Chemistry, 58(4), 317-324.

Rousset M., Triboı E., Branlard G. and Godon B., 1985. Influence du genotype et du milieu sur les tests d'appreciation de la valeur d'utilisation du ble' tendre (Triticum aestium em. Thell.) dans les industries de cuisson. Agronomie,5:653-663.

SAS Institute, 2002. JMP Statistics. Cary, NC, USA: SAS Institute, Inc. pp.707.

Steel G. D. and Torrie J. H., 1980. Principles and Procedures of Statistics: A Biometrical Approach. 2. ed. New York: McGraw-Hill Publ. Company.

Troccoli A., Borrelli G.M., DeVita P., Fares C. and DiFonzo N. 2000. Durum wheat quality: A multidisciplinary concept. Journal of Cereal Science, 32, 99-113.

Veraverbeke, W. S. and Delcour, J. A., 2002. Wheat protein composition and properties ofwheat glutenin in relation to breadmaking functionality. Critical Reviews in Food Science and Nutrition, 42:179-208. 
Karaduman ve ark. "Ekmeklik Buğday Islah Programlarında Gluten Kalitesinin Değerlendirilmesi için GlutoPik Parametrelerinin Kullanılabilirliğinin Araştırılması"

Willams P.C., El-haramein F.J., Nakkaoul H. and Rıhawi, S., 1986. Crop Quality Evaluation Methods and Guidelines. ICARDA. 142 s. Aleppo, Syria.
Zeleny L., 1971. Criteria of wheat quality, in Wheat Chemistry and Technology. Ed by $\mathrm{Y}$. Pomeranz, AACC St Paul, MN, USA. 